\title{
Cadmium induced Drp1-dependent mitochondrial fragmentation by disturbing calcium homeostasis in its hepatotoxicity
}

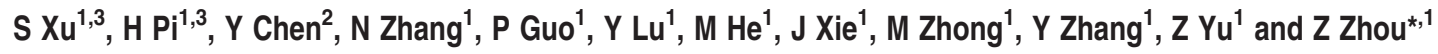

Mitochondria are critical targets in the hepatotoxicity of cadmium (Cd). Abnormal mitochondrial dynamics have been increasingly implicated in mitochondrial dysfunction in pathophysiological conditions. Therefore, our study aimed to investigate the effects and underlying mechanism of $\mathrm{Cd}$ on mitochondrial dynamics during hepatotoxicity. In the L02 liver cell lines, $12 \mu \mathrm{M}$ cadmium chloride $\left(\mathrm{CdCl}_{2}\right)$ exposure induced excessive mitochondrial fragmentation as early as $3 \mathrm{~h}$ post-treatment with $\mathrm{Cd}$, which preceded the mitochondrial dysfunction such as reactive oxygen species (ROS) overproduction, mitochondrial membrane potential $(\Delta \Psi \mathrm{m})$ loss and ATP reduction. Concurrent to mitochondrial fragmentation, $\mathrm{CdCl}_{2}$ treatment increased the protein levels of dynamin-related protein (Drp1) and promoted the recruitment of Drp1 into mitochondria. Strikingly, mitochondrial fragmentation also occurred in the liver tissue of rats exposed to $\mathrm{CdCl}_{2}$, accompanied by enhanced recruitment of Drp1 into mitochondria. Moreover, in L02 cells, Drp1 silencing could effectively reverse Cd-induced mitochondrial fragmentation and mitochondrial dysfunction. Furthermore, the increased expression and mitochondrial recruitment of Drp1 were tightly related to the disturbance of calcium homeostasis, which could be prevented by both chelating $\left[\mathrm{Ca}^{2+}\right]_{\mathrm{i}}$ and inhibiting $\left[\mathrm{Ca}^{2+}\right]_{\mathrm{m}}$ uptake. Overall, our study indicated that $\mathrm{Cd}$ induced Drp1-dependent mitochondrial fragmentation by disturbing calcium homeostasis to promote hepatotoxicity. Manipulation of Drp1 may be the potential avenue for developing novel strategies to protect against cadmium-induced hepatotoxicity.

Cell Death and Disease (2013) 4, e540; doi:10.1038/cddis.2013.7; published online 14 March 2013

Subject Category: Experimental medicine

Cadmium $(\mathrm{Cd})$ is a long-lived environmental and occupational pollutant. Humans are primarily exposed to $\mathrm{Cd}$ from food crops grown in Cd-containing soils, cigarette smoke, pigments, plastics, alloys, electronic compounds and rechargeable nickel-cadmium batteries. The rapid increase in $\mathrm{Cd}$ exposure in modern society has raised considerable concerns about its potential hazardous effects on human health. ${ }^{1-3} \mathrm{Cd}$ is a potential carcinogenic agent and has multiple toxic effects in cadmium-associated diseases. ${ }^{4-6}$ The liver, which is one of the primary target organs of $\mathrm{Cd}$, is critically damaged by acute or chronic exposure to $\mathrm{Cd} .{ }^{7-10}$ Growing evidence indicates that mitochondrial dysfunction plays crucial roles in $\mathrm{Cd}$ induced hepatotoxicity. ${ }^{11-13}$ However, it is still unclear exactly what roles mitochondrial dysfunction plays in the hepatotoxicity of Cd. A great deal of research effort has been directed toward mitochondria in the investigation of the mechanisms underlying $\mathrm{Cd}$-induced hepatotoxicity and in the exploration of potential therapeutic strategies.

Recently, mitochondria have proved to be highly dynamic organelles that undergo constant fission and fusion, activities that are orchestrated by large dynamin-related GTPases. ${ }^{14}$ These dynamic mitochondrial processes not only control mitochondrial morphology and size, but also impact mitochondrial function by enabling content exchange between mitochondria. Impairments in mitochondrial dynamics markedly contribute to mitochondrial dysfunction in various pathophysiological conditions and mitochondria-associated diseases. ${ }^{15,16}$ Accumulating evidence has indicated that abnormal mitochondrial fission, mediated by dynamin-related protein 1 (Drp1), leads to excessive mitochondrial fragmentation, which is a common pathway that leads to mitochondrial dysfunction critical to cellular death. ${ }^{17-19}$ In light of the profound impact of mitochondrial dynamics have on mitochondrial function, the present study aims to provide insight into the effects and underlying mechanism of $\mathrm{Cd}$ on mitochondrial dynamics in its hepatotoxicity.

\section{Results}

$\mathrm{CdCl}_{2}$ induced mitochondrial fragmentation in L02 cells. To explore the effects of $\mathrm{Cd}$ on mitochondrial dynamics in liver injuries, mitochondrial morphology was examined in the human normal liver cell line L02 following exposure to $12 \mu \mathrm{M}$ cadmium chloride $\left(\mathrm{CdCl}_{2}\right)$. Confocal microscopy analysis

\footnotetext{
${ }^{1}$ Department of Occupational Health, Third Military Medical University, Chongqing, People's Republic of China and ${ }^{2}$ Institute of Hepatobiliary Surgery, Southwest Hospital, Third Military Medical University, Chongqing, People's Republic of China

${ }^{*}$ Corresponding author: Z Zhou, Department of Occupational Health, Third Military Medical University, No. 30 Gaotanyan Street, Shapingba District, Chongqing 400038, China. Tel: + 8623 68752290; Fax: + 8623 68752290; E-mail: xscsci2009@yahoo.cn

${ }^{3}$ These authors contributed equally to this work

Keywords: cadmium; hepatotoxicity; mitochondrial fragmentation; mitochondrial dysfunction; dynamin-related protein (Drp1)

Abbreviations: Drp1, dynamin-related protein 1; Cd, cadmium; $\mathrm{CdCl}_{2}$, cadmium chloride; ROS, reactive oxygen species; $\Delta \Psi \mathrm{m}$, mitochondrial membrane potential; $\mathrm{Ca}^{2+}$, calcium; MDA, malondialdehyde; Mfn1, mitofusin 1; Mfn2, mitofusin 2; OPA1, optic atrophy 1; Fis1, fission 1

Received 20.11.12; accepted 19.12.12; Edited by A Finazzi-Agró
} 
revealed that the mitochondria of L02 cells in the untreated control groups exhibited normal elongated-tubular structures. However, after L02 cells were exposed to $12 \mu \mathrm{M} \mathrm{CdCl}_{2}$ for various time periods $(0,3,6,12$ and $24 \mathrm{~h})$, the morphology of mitochondria gradually changed into significant punctuated structures (Figure 1a). To further confirm this morphological phenomenon, the mitochondria were tracked in real time by using time-lapse microscopy as soon as the L02 cells exposed to $\mathrm{CdCl}_{2}$. Fluorescence imaging revealed that the tubular network of mitochondria changed into pronounced punctuated structures in a time-dependent manner, which occurred as early as $3 \mathrm{~h}$ after $\mathrm{CdCl}_{2}$ treatment (Figure $1 \mathrm{~b}$ ). These results indicated that $\mathrm{CdCl}_{2}$ significantly induced mitochondrial fragmentation in L02 cells.

Mitochondrial fragmentation preceded mitochondrial dysfunction in $\mathbf{C d C l}_{2}$-treated $\mathbf{L O 2}$ cells. To explore the temporal relationship between the alteration of mitochondrial dynamics and mitochondrial dysfunction in the hepatotoxicity of $\mathrm{CdCl}_{2}$, we carried out time-course studies to assay the effects of $\mathrm{Cd}$ on various mitochondrial parameters in L02 cells. As shown in figure, until $6 \mathrm{~h}$ after exposure, $\mathrm{CdCl}_{2}$ significantly increased reactive oxygen species (ROS) production (Figure $2 \mathrm{a}$ ) and reduced $\Delta \Psi \mathrm{m}$ (Figure $2 \mathrm{~b}$ ) in a time-dependent manner. Following this damage, the contents of ATP were clearly decreased beginning $12 \mathrm{~h}$ after exposure (Figure 2c). In addition to mitochondrial dysfunction, cell viability in the $\mathrm{CdCl}_{2}$-treated $\mathrm{L} 02$ cells underwent a time-dependent reduction (Figure $2 \mathrm{~d}$ ). These results indicated that mitochondrial fragmentation occurred before mitochondrial dysfunction in $\mathrm{Cd}$ hepatotoxicity in vitro.

Mitochondrial fragmentation occurred in the injured liver tissue of rats exposed to $\mathbf{C d C l}_{2}$. To investigate whether mitochondrial fragmentation was also involved in the $\mathrm{CdCl}_{2}$ hepatotoxicity in vivo, rats were intraperitoneally injected with 1 or $2 \mathrm{mg} / \mathrm{kg} \mathrm{CdCl}_{2}$ for 14 days. As to mitochondrial morphology, electron microscopy studies presented normal elongated-tubular structures in the livers of the control group, whereas the livers of the $\mathrm{CdCl}_{2}$-treated rats had an increased number of smaller mitochondria with fragmented and spotted structures (Figure 3A). In addition, the MDA levels were significantly increased in the livers of rats exposed to $\mathrm{CdCl}_{2}$ compared with the control group (a 53 and $177 \%$ elevation for 1 and $2 \mathrm{mg} / \mathrm{kg} \mathrm{CdCl}$, respectively) (Figure 3B). Conversely, ATP contents were significantly decreased in the livers after exposure to $\mathrm{CdCl}_{2}$ (Figure $3 \mathrm{C}$ ). Light microscopy revealed that $\mathrm{CdCl}_{2}$ exposure induced focal necrosis and inflammatory cell infiltration into the livers of rats. At $2 \mathrm{mg} / \mathrm{kg}$, more severe and widespread 'ballooning degeneration' was observed (Figure 3D). These findings indicated that mitochondrial fragmentation associated with mitochondrial dysfunction was also involved in the hepatotoxicity of $\mathrm{Cd}$ in vivo.

$\mathrm{CdCl}_{2}$ exposure increased Drp1 expression and enhanced mitochondrial recruitment. To explore the mechanism by which mitochondrial dynamics were impaired during $\mathrm{Cd}$ induced hepatotoxicity, we investigated the effects of $\mathrm{CdCl}_{2}$ on the expression of mitochondrial fusion proteins (i.e., Mfn1, Mfn2 and OPA1) and fission proteins (i.e., Drp1 and Fis1).
Western blot analysis revealed that 1 and $2 \mathrm{mg} / \mathrm{kg} \mathrm{CdCl}$ significantly increased the protein levels of Drp1 by 35 and $70 \%$, respectively. Additionally, $2 \mathrm{mg} / \mathrm{kg} \mathrm{CdCl} 2$ decreased the protein levels of Mfn1 by $56 \%$, whereas $1 \mathrm{mg} / \mathrm{kg} \mathrm{CdCl}$ did not have any effect on Mfn1 protein levels (Figures $4 a$ and b). In L02 cells, only the protein levels of Drp1 were significantly increased in a time-dependent manner at $3 \mathrm{~h}$ after the cells were treated with $\mathrm{CdCl}_{2}$ (Figures $4 \mathrm{c}$ and $\mathrm{d}$ ). Furthermore, in isolated mitochondria from both rats liver tissue and L02 cells, $\mathrm{CdCl}_{2}$ exposure increased the mitochondrial Drp1 protein levels (Figures 5a-d). Consistent with the increase in mitochondrial Drp1 protein levels, confocal microscopy showed that $\mathrm{CdCl}_{2}$ significantly promoted the translocation of Drp1 from the cytoplasm into mitochondria (Figure 5e). These results indicated that Drp1 played critical roles in Cdinduced mitochondrial fragmentation.

Drp1 silencing attenuated $\mathrm{CdCl}_{2}$-induced mitochondrial fragmentation and mitochondrial dysfunction in L02 cells. The above in vitro and in vivo results both demonstrated that $\mathrm{Cd}$-induced mitochondrial fragmentation had a correlation with the Drp1. This correlation raised a possibility that Drp1 siRNA could protect against the hepatotoxicity of Cd. After cells were successfully transfected with Drp1 siRNA, Drp1 silencing was found to efficiently reverse mitochondrial fragmentation in the cells treated by $12 \mu \mathrm{M}$ $\mathrm{CdCl}_{2}$ for $12 \mathrm{~h}$ (Figure $6 \mathrm{~b}$ ). The resulting maintenance of mitochondrial morphology was beneficial for mitochondrial turnover. Indeed, following a reduction in mitochondrial fragmentation, various types of mitochondrial dysfunction, including ROS overproduction, ATP decline and $\triangle \Psi \mathrm{m}$ loss, were efficiently attenuated in $\mathrm{CdCl}_{2}$-treated cells transfected with Drp1 siRNA (Figures 6c-e). In line with these results, Drp1 silencing successfully ameliorated the damage to cell viability caused by Cd in L02 cells (Figure 6f).

The effects of $\mathbf{C d C l}_{2}$ on Drp1 were associated with $\left[\mathrm{Ca}^{2+}\right]_{\mathrm{i}}$ elevation and $\left[\mathrm{Ca}^{2+}\right]_{\mathrm{m}}$ uptake. For calcium homeostasis is closely associated with Drp1 function, we finally monitored the concentrations of $\left[\mathrm{Ca}^{2+}\right]_{\mathrm{i}}$ and $\left[\mathrm{Ca}^{2+}\right]_{\mathrm{m}}$ in $\mathrm{Cd}-$ treated $\mathrm{LO2}$ cells using the calcium indicators Fluo 3-AM and Rhod-2, respectively. As early as $2 \mathrm{~h}$ after Cd treatment, both $\left[\mathrm{Ca}^{2+}\right]_{\mathrm{i}}$ and $\left[\mathrm{Ca}^{2+}\right]_{\mathrm{m}}$ were significantly increased in a timedependent manner (Figure 7a). In addition, pre-treatment with specific $\left[\mathrm{Ca}^{2+}\right]_{i}$ chelator, BAPTA-AM, reduced both Drp1 expression and Drp1 recruitment into mitochondria (Figures $7 \mathrm{~b}-\mathrm{f})$. Pre-treatment with an inhibitor of $\left[\mathrm{Ca}^{2+}\right]_{\mathrm{m}}$ uptake, Ru360, also decreased the recruitment of Drp1 to mitochondria, but had no effect on Drp1 protein levels (Figures 7b-f). Moreover, pre-treatment with both BAPTA-AM and Ru360 efficiently reduced Drp1-mediated mitochondrial fragmentation (Figure 7f). These results indicated that Cd-induced Drp1-dependent mitochondrial fragmentation was closely associated with $\left[\mathrm{Ca}^{2+}\right]_{\mathrm{i}}$ elevation and $\left[\mathrm{Ca}^{2+}\right]_{\mathrm{m}}$ uptake.

\section{Discussion}

The present study provided evidence that $\mathrm{Cd}$ exposure led to pronounced mitochondrial fragmentation both in L02 cells and in the livers of rats exposed to $\mathrm{CdCl}_{2}$. Additionally, 
a

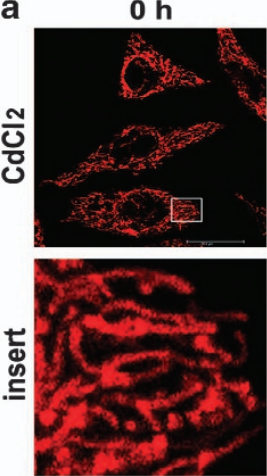

$3 \mathrm{~h}$
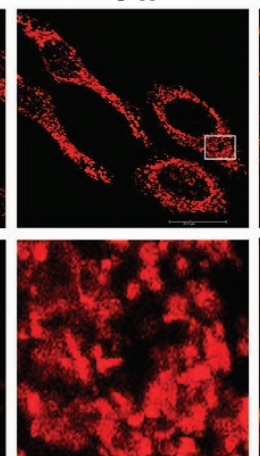

$6 \mathrm{~h}$
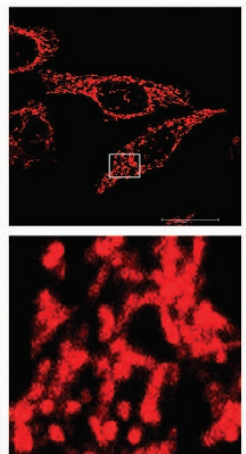

$12 \mathrm{~h}$
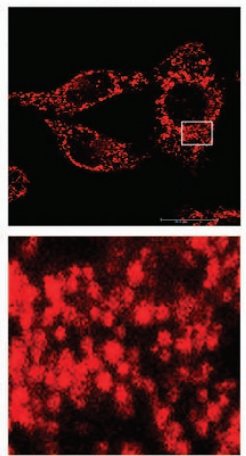

$24 \mathrm{~h}$
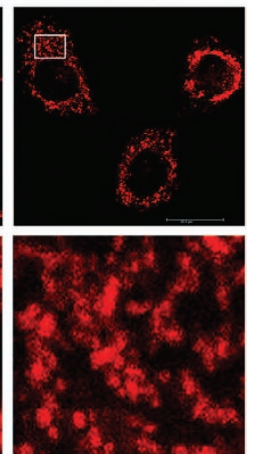
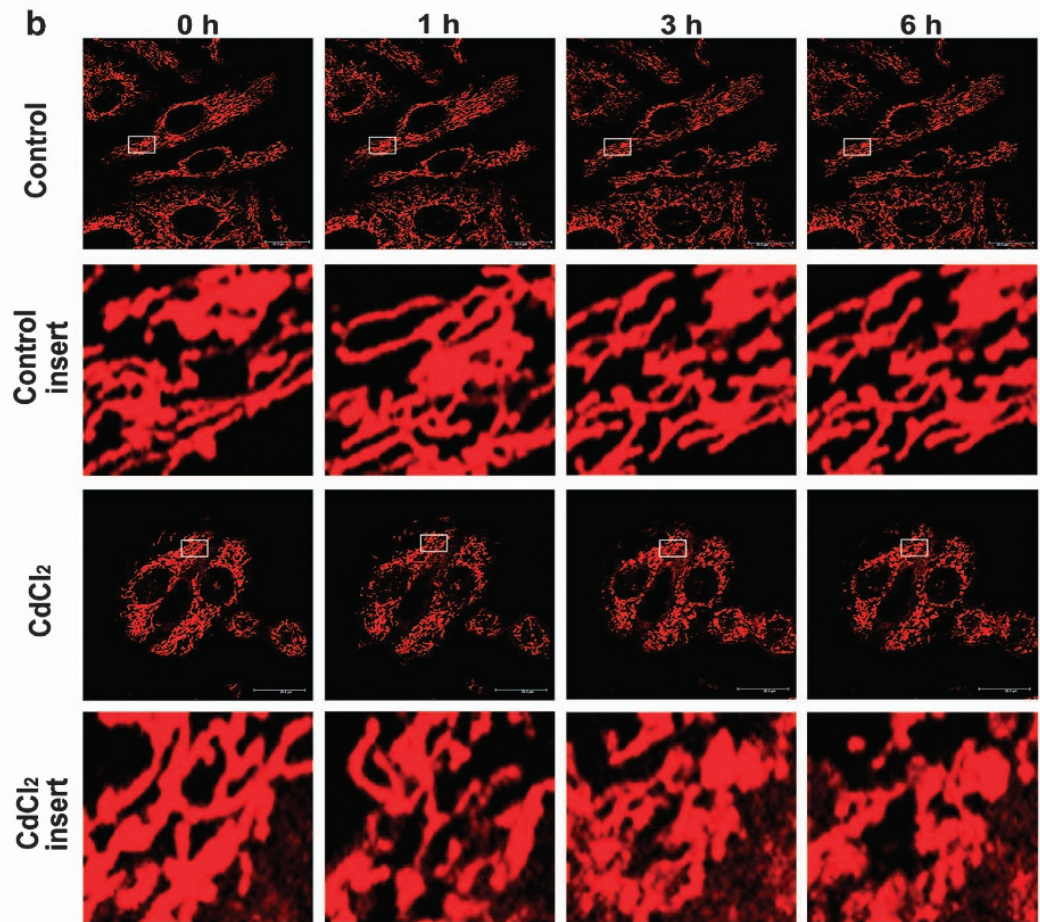

Figure $1 \mathrm{CdCl}_{2}$ exposure triggered mitochondrial fragmentation in L02 cells. A mitochondria-specific fluorescence probe, MitoTracker Red CMXRos (red), was applied to detect the alterations of mitochondrial morphology. After $\mathrm{L} 02$ cells were treated with $12 \mu \mathrm{M} \mathrm{CdCl}_{2}$, (a) representative changes in mitochondrial morphology were detected by confocal microscopy at various time points $(0,3,6,12$ and $24 \mathrm{~h}$ ). (b) Representative individual mitochondria were tracked in real time using time-lapse microscopy immediately after $\mathrm{L} 02$ cells were exposed to $12 \mu \mathrm{M} \mathrm{CdCl}$

Cd-triggered mitochondrial fragmentation preceded mitochondrial damage in vitro and was associated with $\mathrm{Cd}$ induced mitochondrial dysfunction in vivo. Consistent with inducing excessive mitochondrial fragmentation, Cd exposure significantly increased protein levels of Drp1 and promoted the recruitment of Drp1 into mitochondria, which was tightly associated with the disturbance of calcium homeostasis. Furthermore, Drp1 silencing, as well as the use of agents that interfere with $\left[\mathrm{Ca}^{2+}\right]_{\mathrm{i}}$ and $\left[\mathrm{Ca}^{2+}\right]_{\mathrm{m}}$, were found to efficiently prevent mitochondrial fragmentation, thereby attenuating mitochondrial dysfunction in Cd-treated L02 cells. Our study indicated that $\mathrm{Cd}$ exposure induced Drp1-dependent mitochondrial fragmentation by disturbing $\mathrm{Ca}^{2+}$ homeostasis that contributed to mitochondrial dysfunction in its hepatotoxicity. To the best of our knowledge, the present study is the first to investigate the mechanism of $\mathrm{Cd}$ hepatotoxicity focusing on the impairment of mitochondrial dynamics.
The accelerated applications of $\mathrm{Cd}$ in modern society raise the risk of causing adverse effects on human health. Both acute and chronic $\mathrm{Cd}$ exposures have numerous undesirable effects on liver tissue. It is well documented that mitochondrial dysfunction is involved in the hepatotoxicity of $\mathrm{Cd}$ due to its unique structural and functional characteristics ${ }^{11,12,20,21}$ The interactions between $\mathrm{Cd}$ and mitochondria have been emphasized as the critical events in $\mathrm{Cd}$ hepatotoxicity, however, it is unclear exactly how these interactions lead to mitochondrial damage to date. Recently, mitochondria were proved to be highly dynamic organelles that have a profound impact in mitochondrial and cellular function. ${ }^{14-16}$ The disturbed mitochondrial dynamics have broad significance with respect to providing insight into novel mechanisms for several well-documented mitochondrial defects, such as in neurodegenerative diseases, cardiovascular disorders and diabetes mellitus. ${ }^{16,22-24}$ Thus, it is well worth investigating 

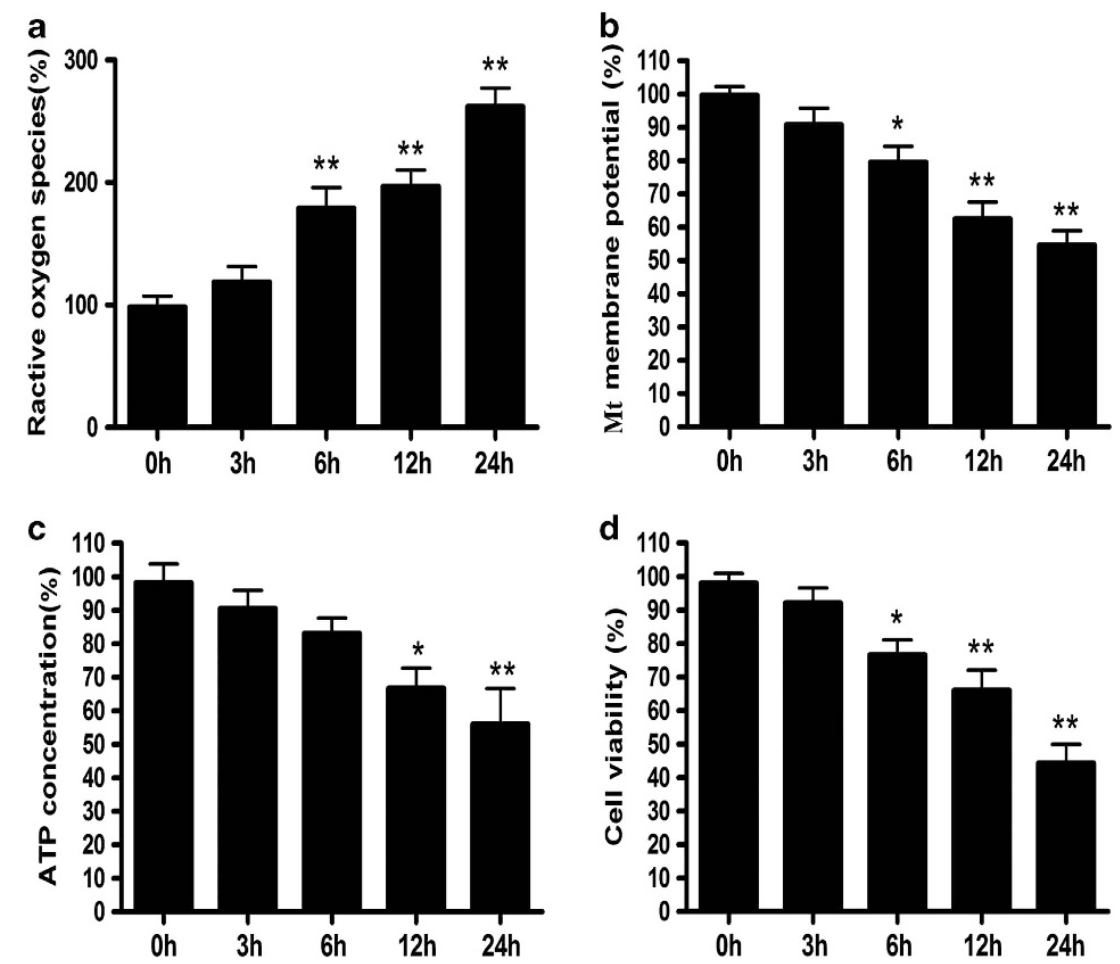

Figure $2 \mathrm{CdCl}_{2}$ exposure induced mitochondrial dysfunction in a time-dependent manner in L02 cells. (a) ROS production, (b) $\Delta \Psi \mathrm{m}$, (c) ATP contents and (d) cell viability were assayed after L02 cells were treated with $12 \mu \mathrm{M} \mathrm{CdCl}_{2}$ for various time periods $(0,3,6,12$ and $24 \mathrm{~h})$. The results are expressed as a percentage of the control, which was set at $100 \%$. The values are presented as the mean \pm S.E.M., all experiments were repeated six times, ${ }^{*} P<0.05,{ }^{* *} P<0.01$ versus the control group

whether abnormal mitochondrial dynamics are related to Cd-induced mitochondrial damage.

Mitochondrial dynamics are regulated by the delicate balance of mitochondrial fusion and fission. Any disturbances in mitochondrial dynamics may be promptly reflected by changes in mitochondrial morphology. ${ }^{14-16}$ In the present study, Cd exposure significantly induced the changes of mitochondrial morphology from elongated-tubular and filamentous networks to small and spherical structures both in L02 cells and in rat liver tissue. According to previous reports, these morphological changes indicated that mitochondrial fragmentation was involved in the hepatotoxicity of $\mathrm{Cd}$, which may lead to mitochondrial damage through hampering the mixture and exchange of mitochondrial contents. ${ }^{14-16}$ This damage could explain why $\mathrm{Cd}$ exposure disturbed mitochondrial structures, altered the mitochondrial permeability transition, inhibited the respiratory chain reaction pathway, induced oxidative stress and reduced ATP contents in others' studies and in ours. ${ }^{12,13,20,25,26}$

Mitochondrial fragmentation seems to be an early, upstream event in mitochondrial dysfunction in the hepatotoxicity of Cd. Real-time morphology analysis indicated that mitochondrial fragmentation occurred as early as $3 \mathrm{~h}$ after L02 cells were exposed to $\mathrm{CdCl}_{2}$. Consistently, the protein levels of Drp1, the key mitochondrial fission mediator, were significantly increased, and Drp1 was recruited into mitochondria. These results indicated that $\mathrm{Cd}$-induced mitochondrial fission occurred earlier than mitochondrial dysfunction, which only changed over a 6-h period in $\mathrm{CdCl}_{2}$-treated L02 cells. Importantly, silencing of Drp1 inhibited the toxic effects of $\mathrm{CdCl}_{2}$ on the overwhelming mitochondrial fission, followed by the turnover of mitochondrial dysfunction. The present results suggest that mitochondrial fragmentation not only precedes mitochondrial dysfunction but is also required for mitochondrial dysfunction in the hepatotoxicity of $\mathrm{Cd}$. These data were consistent with recent reports, demonstrating that excessive mitochondrial fragmentation mediated by fission is essential for oxidative stress and mitochondrial dysfunction. ${ }^{17,18}$

The dynamic balance of mitochondrial fusion and fission is usually mediated by five large dynamin-related GTPases. Fusion involves the Mfn1, Mfn2 and OPA1 proteins, whereas fission requires the Drp1 and Fis1 proteins. ${ }^{14,22,27}$ In Cdtreated L02 cells, only the protein levels of Drp1 significantly increased, while the levels of the other four dynamin-related proteins did not exhibit any changes. In addition, the increased Drp1 was found to largely translocated into mitochondria. This finding suggested that the increased Drp1 is recruited to punctuate spots on the mitochondrial surface to mediate mitochondrial fission. ${ }^{28}$ The importance of Drp1 was also confirmed in the injured liver tissue of rats exposed to Cd. Importantly, manipulation Drp1 by siRNA efficiently blocked $\mathrm{CdCl}_{2}$-induced mitochondrial fragmentations, which profited for rescuing mitochondrial dysfunction and cell damage. In agreement with our study, other experimental models have shown that inhibition of Drp1 function and overexpression of dominant-negative Drp1 are effective in preventing mitochondrial fission and mitochondrial-dependent cell death. ${ }^{17-19,29}$ Thus, our study demonstrated that Drp1 plays a critical role in the mitochondrial 


\section{A}
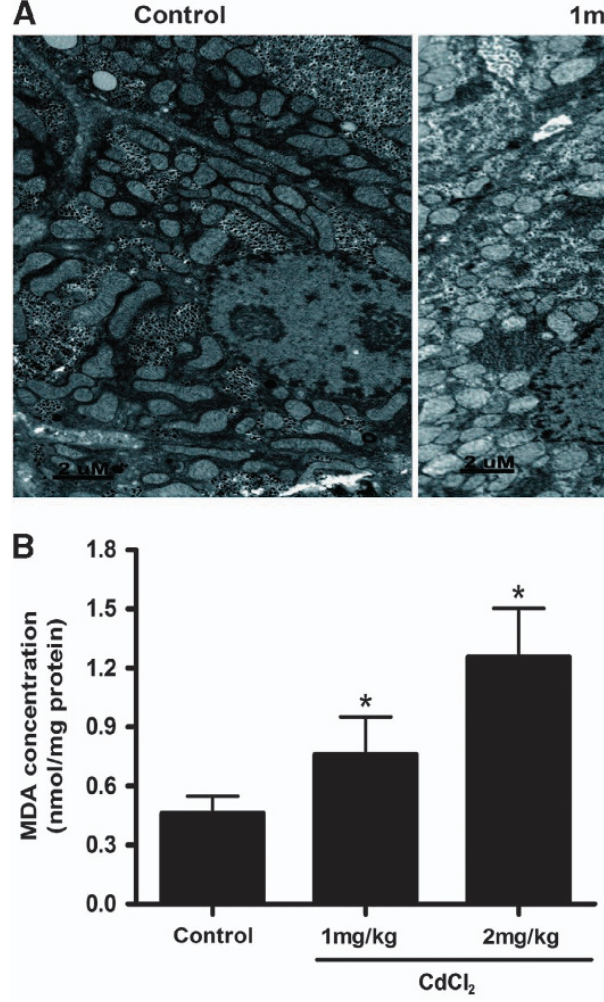

D
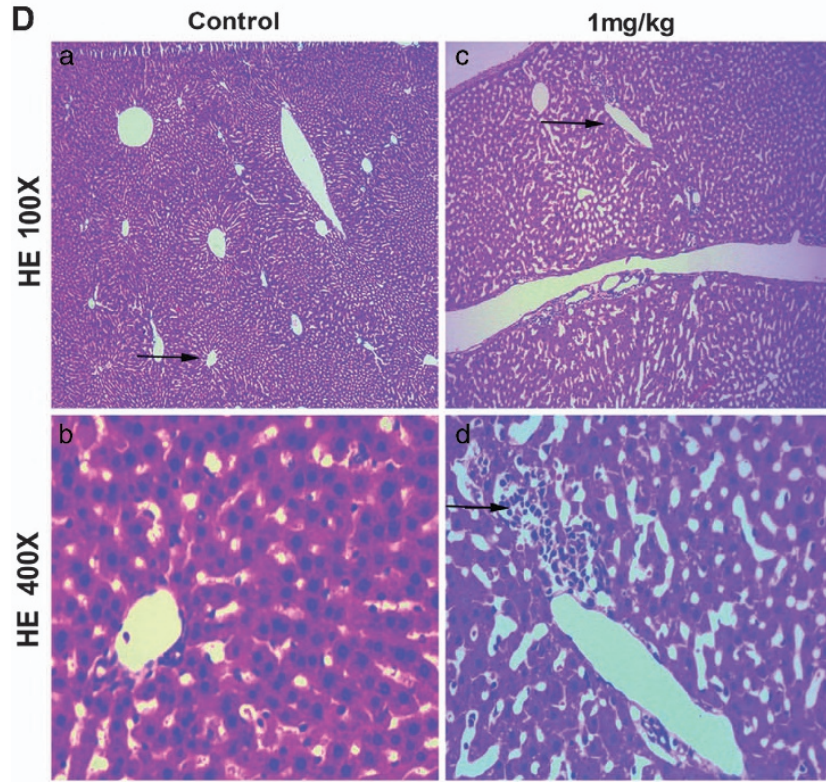

$1 \mathrm{mg} / \mathrm{kg}$

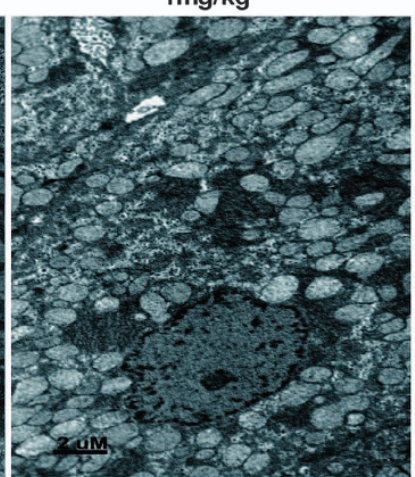

$c$
$2 \mathrm{mg} / \mathrm{kg}$

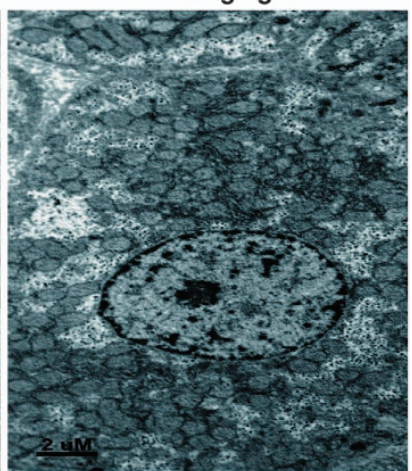

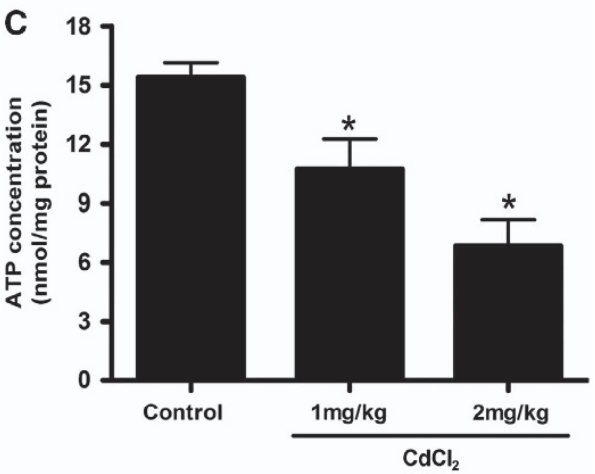

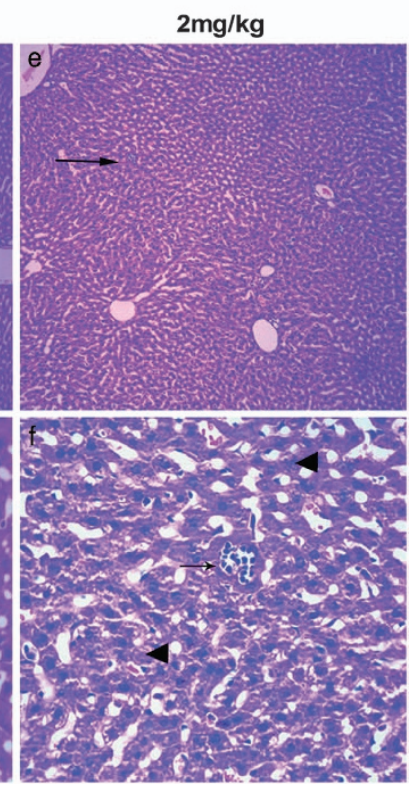

Figure 3 Mitochondrial fragmentation occurs in the injured liver tissue of rats exposed to $\mathrm{CdCl}_{2}$. (A) Representative mitochondrial morphology in rat liver tissue as detected by electron microscopy. (B) MDA concentrations in rat liver tissue were measured using the TBA method. (C) ATP contents in rat liver tissue were determined using an ATP Determination Kit. Both MDA concentrations and ATP contents were expressed as nmol/mg protein. The values are presented as the mean \pm S.E.M., all experiments were repeated six times, ${ }^{*} P<0.05$ versus control group. (D) Representative histology of rat livers. (a) No obvious structural abnormalities were detected in the control liver sections. Liver sections of rats administered $1 \mathrm{mg} / \mathrm{kg}$ (c) or $2 \mathrm{mg} / \mathrm{kg}$ (e) $\mathrm{CdCl}_{2}$ presented representative focal necrosis and inflammatory cell infiltration. Panels (b), (d) and (f) show the enlarged sections of $(\mathbf{a}),(\mathbf{c})$ and $(\mathbf{e})$, respectively $(\rightarrow)$. ((a), (c), (e) magnification, $\times 100 ;(\mathbf{b}),(\mathbf{d}),(\mathbf{f})$ magnification $\times 400)$. Hepatic tissues of the Cd-treated rats, showing representative focal necrosis $(\rightarrow)$ and inflammatory cell infiltration $(\triangleleft)$

fragmentation and mitochondrial dysfunction in the hepatotoxicity of Cd.

It is likely that Cd exposure increased Drp1 expression and its mitochondrial recruitment through disturbing $\mathrm{Ca}^{2+}$ homeostasis. In the present study, Cd exposure was found to initiate $\left[\mathrm{Ca}^{2+}\right]_{\mathrm{i}}$ elevation coupled with $\left[\mathrm{Ca}^{2+}\right]_{\mathrm{m}}$ uptake in L02 cells. Either chelating $\left[\mathrm{Ca}^{2+}\right]_{\mathrm{i}}$ or inhibiting $\left[\mathrm{Ca}^{2+}\right]_{\mathrm{m}}$ uptake efficiently prevented the mitochondrial recruitment of 

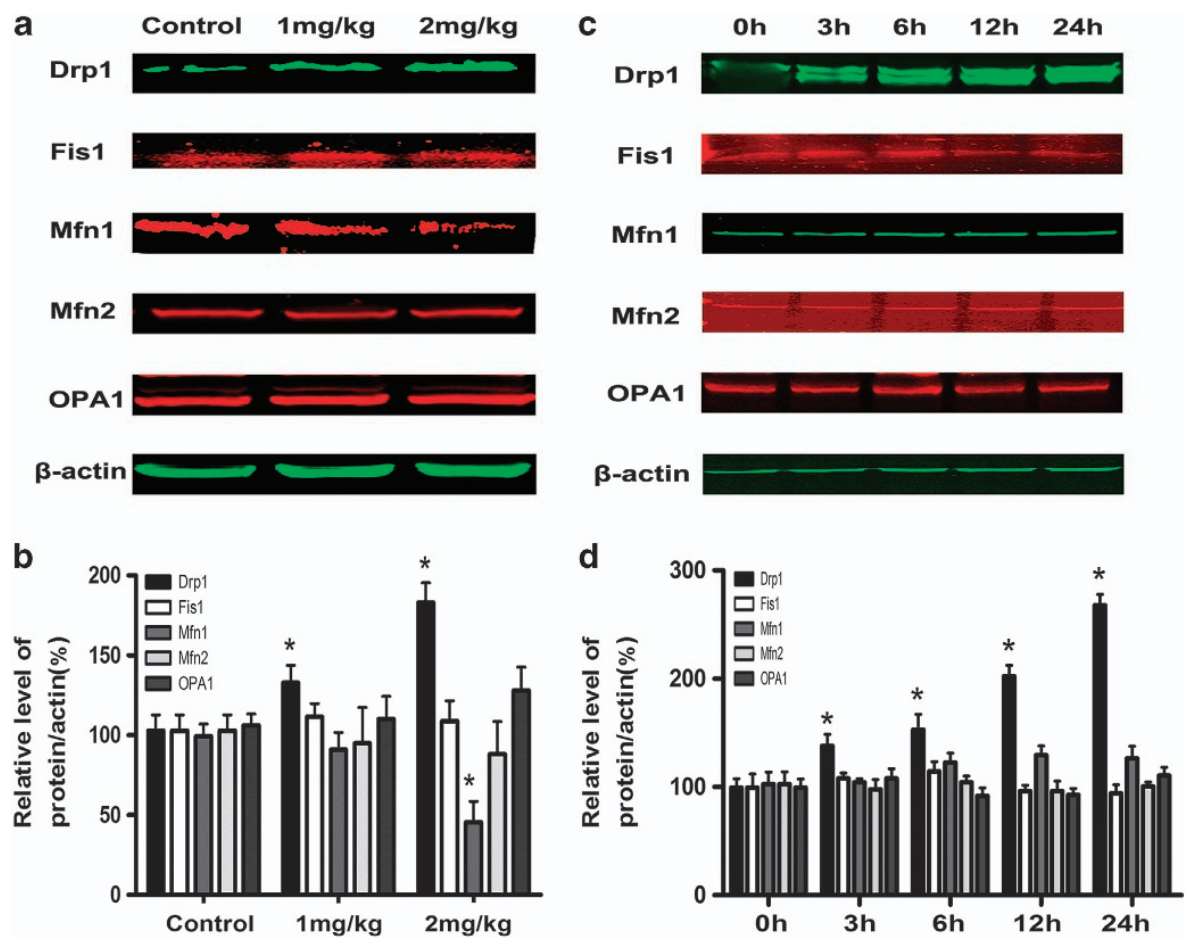

Figure 4 The effects of $\mathrm{CdCl}_{2}$ on mitochondrial fusion/fission proteins expression. Representative immunoblot of the protein levels of Drp1 (84 kDa), Fis1 (17 kDa), Mfn1 (86 kDa), Mfn2 (86 kDa) and OPA1 (112 kDa) in rats liver tissue (a) and in L02 cells (c). $\beta$-Actin (42 kDa) was chosen as an internal standard for the amount of protein loaded for each sample. The quantification analysis in figures (b) and (d) are for figures (a) and (c), respectively. The data are representative of six independent experiments. The results are expressed as a percentage of control set at $100 \%$. The values are expressed as mean \pm S.E.M., ${ }^{*} P<0.05$ versus the control group

Drp1, followed by a reduction of mitochondrial fragmentation. Based on previous studies, it could be speculated that $\mathrm{Cd}$ induced $\left[\mathrm{Ca}^{2+}\right]_{i}$ elevation may activate the calcineurindependent dephosphorylation of Drp1 and regulate Drp1 translocation into mitochondria. ${ }^{30-32}$ In addition, the increased $\left[\mathrm{Ca}^{2+}\right]_{\mathrm{m}}$ also directly enhanced Drp1 recruitment to the mitochondria, possibly through structural changes in mitochondrial permeability transition proteins. ${ }^{31-33}$ However, there is at least one difference in the way $\left[\mathrm{Ca}^{2+}\right]_{\mathrm{i}}$ and $\left[\mathrm{Ca}^{2+}\right]_{\mathrm{m}}$ regulate Drp1 recruitment. We found that a $\left[\mathrm{Ca}^{2+}\right]_{i}$ chelator could reverse the increase of Drp1 protein levels while a $\left[\mathrm{Ca}^{2+}\right]_{\mathrm{m}}$ inhibitor had no effect. It suggested that except for regulating Drp1 mitochondrial recruitment, $\left[\mathrm{Ca}^{2+}\right]_{i}$ was also responsible for the increase in Drp1 expression, which may provide the molecular basis for Drp1 recruitment.

Taken together, the present data demonstrated that pronounced mitochondrial fragmentation is evident in Cdinduced hepatotoxicity. Given the temporal relationship between mitochondrial dynamics alteration and mitochondrial dysfunction, excessive mitochondrial fragmentation may provide a new perspective from which to understand the mechanisms that underlie $\mathrm{Cd}$-induced mitochondrial dysfunction in liver injuries. In this regard, it is worth noting Drp1, a key mediator of mitochondrial fission, plays a critical role in mitochondrial fragmentation. Hence, the manipulation of Drp1 may offer new strategies to combat the hepatotoxicity induced by cadmium.
Materials and Methods

Cell culture and treatment. The human normal liver cell line L02 was purchased from the Cell Bank of the Institute of Biochemistry and Cell Biology (Shanghai, China). The L02 cells were cultured in RPMl1640 medium (Invitrogen Corp., Carlsbad, CA, USA) supplemented with $5 \%$ heat-inactivated FCS (HyClone, Logan, UT, USA), and 1\% v/v penicillin/streptomycin (Sigma-Aldrich, St. Louis, $\mathrm{MO}, \mathrm{USA}$ ) in a $5 \% \mathrm{CO}_{2}$ humidified atmosphere at $37^{\circ} \mathrm{C}$. The $\mathrm{L} 02$ cells were grown to $80 \%$ confluence and exposed to $12 \mu \mathrm{M} \mathrm{CdCl}_{2}$ (Sigma-Aldrich) for various periods of time $(0,3,6,12$ and $24 \mathrm{~h})$. The $\mathrm{CdCl}_{2}$ was dissolved in distilled and deionized water to produce a 12-mM stock solution, which was then used to dilute the cell culture medium before application.

Animal exposure. Eighteen adults (8 weeks old, 180-220 g) male Sprague Dawley (SD) rats were purchased from the Experimental Animal Center of the Third Military Medical University (Chongqing, China). The rats were housed under standard conditions with a 12-h light-dark cycle and a constant temperature $\left(22 \pm 2^{\circ} \mathrm{C}\right)$. For the experiments involving $\mathrm{Cd}$ exposure, randomly selected rats were intraperitoneally injected with $1 \mathrm{mg} / \mathrm{kg}(n=6)$ or $2 \mathrm{mg} / \mathrm{kg}(n=6) \mathrm{CdCl}_{2}$ for 14 days. The $\mathrm{CdCl}_{2}$ was dissolved in $0.9 \%$ physiological saline. An additional six randomly selected rats were intraperitoneally injected with $0.9 \%$ physiological saline to serve as the controls. Rats were sacrificed by decapitation $24 \mathrm{~h}$ after the final injection of $\mathrm{Cd}$, and their livers were harvested for analysis. All of these procedures were approved by the Chinese Ministry of Science and Technique for the Accreditation of Laboratory Animal Care.

Confocal laser microscopy. To measure changes in the mitochondrial morphology in L02 cells, the $\mathrm{CdCl}_{2}$-treated cells were reacted with $200 \mathrm{nM}$ MitoTracker Red CMXRos probe (Invitrogen Corp., Carlsbad, CA, USA) for 30 min at $37^{\circ} \mathrm{C}$ according to the manufacturer's instructions. After being washed twice in cold PBS, the live cells were visualized under a Leica confocal laser scanning microscope (TCS SP2, Wetzlar, Germany). MitoTracker Red was monitored at $579 \mathrm{~nm}$ for 

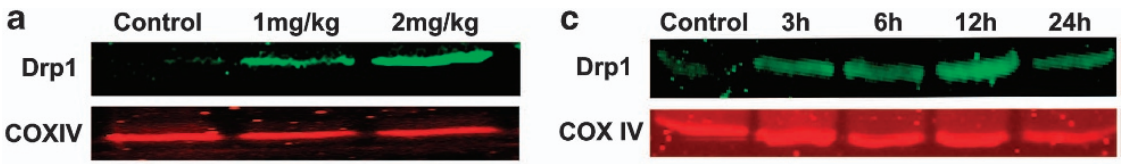

b

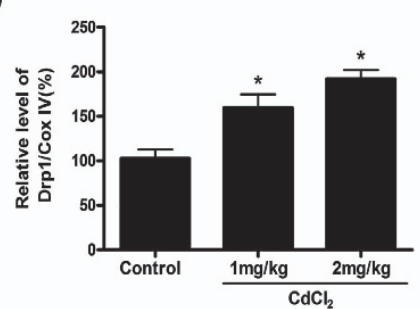

d

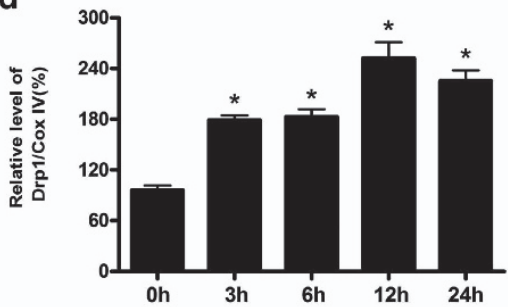

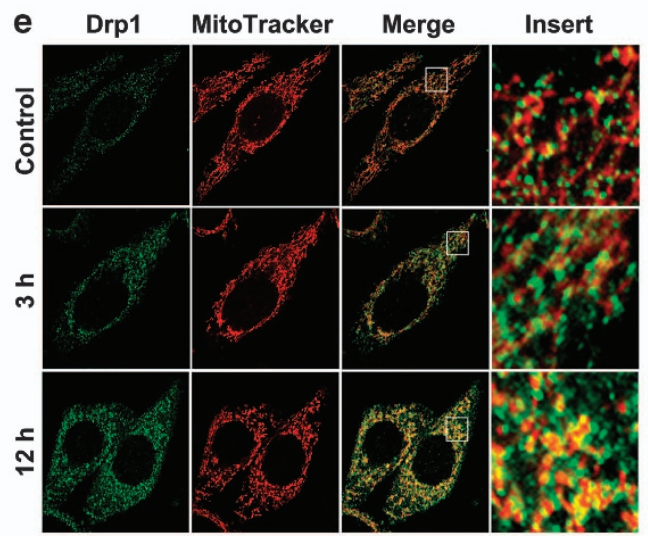

Figure $5 \mathrm{CdCl}_{2}$ exposure enhanced mitochondrial recruitment of Drp1. Representative immunoblot of the protein levels of Drp1 (84 kDa) in mitochondria isolated from rat liver tissue (a) and L02 cells (c). The quantification analysis in figures (b) and (d) are for figures (a) and (c), respectively. (e) Confocal microscope scanning photographs indicated increased mitochondrial localization of Drp1 after L02 cells were exposed to $\mathrm{CdCl}_{2}$. Red: Mito-Tracker Red CMXRos, Green: Drp1

excitation and at $599 \mathrm{~nm}$ for emission. In accordance with a previous study, ${ }^{34}$ the fragmented mitochondria were recognized as shortened, punctate and sometimes rounded organelles, whereas filamentous mitochondria had a thread-like tubular structure.

To analyze the translocation of Drp1 into mitochondria, after being incubated with MitoTracker Red CMXRos probe, cells were fixed with $4 \%(\mathrm{w} / \mathrm{v})$ paraformaldehyde in PBS at $4{ }^{\circ} \mathrm{C}$ for $20 \mathrm{~min}$. The cells were then permeabilized with $0.5 \%$ Triton $\mathrm{X}-100$ in PBS for $15 \mathrm{~min}$ at room temperature. The cells were washed twice with PBS before being blocked with normal goat serum at $37^{\circ} \mathrm{C}$ for $30 \mathrm{~min}$. Subsequently, the cells were incubated with a mouse monoclonal antibody against human Drp1 (Santa Cruz Biotechnology, Santa Cruz, CA, USA) at a 1:50 dilution overnight at $4{ }^{\circ} \mathrm{C}$, and then with an Alexa Fluor 488 goat anti-mouse IgG $(\mathrm{H}+\mathrm{L})$ (Invitrogen Corp. Carlsbad, CA, USA) at a $1: 100$ dilution for $1 \mathrm{~h}$ at $37^{\circ} \mathrm{C}$. The cells were mounted in mounting medium and visualized under a Leica confocal laser scanning microscope.

Time-Lapse microscopy. L02 cells were seeded on glass-bottomed dishes. After the mitochondria were labeled with the MitoTracker Red CMXRos probe, the cells were exposed to $\mathrm{CdCl}$ 2. Individual mitochondria were tracked in real time by using a Leica confocal laser scanning microscope. As previously described, ${ }^{17,19}$ images were acquired every $10 \mathrm{~min}$ for $6 \mathrm{~h}$. During the experiment, the cells were placed in a well-equipped live imaging station with a controlled temperature at $37^{\circ} \mathrm{C}$, humidity and $95 \%$ air $/ 5 \% \mathrm{CO}_{2}$.

Oxidative stress determination. The level of oxidative stress in L02 cells was determined by measuring the oxidation of DCFH-DA (Beyotime Company, Shanghai, China) as previously described. ${ }^{35}$ The cellular fluorescence intensity was expressed as the fold change relative to the level observed in the control cells. The oxidative stress in rat liver tissue was measured using a Lipid Peroxidation MDA Assay Kit (Beyotime Company) according to the manufacturer's instructions. The experiment was repeated six times, and the MDA levels were expressed as nmol/mg protein.

Measurement of mitochondrial membrane potential $(\Delta \Psi \mathrm{m})$. A mitochondrial membrane potential assay kit with JC-1 (Invitrogen Corp., Carlsbad, CA, USA) was used to measure the $\Delta \Psi \mathrm{m}$ in L02 cells. Briefly, $1 \times 10^{4}$ cells were plated in a 96-well plate for incubation with $1 \times \mathrm{JC}$ - 1 in growth medium at $37^{\circ} \mathrm{C}$ for $20 \mathrm{~min}$. The resulting green and red fluorescence intensities were detected using an Infinite M200 Microplate Reader (Tecan, Mannedorf, Switzerland). The $\Delta \Psi \mathrm{m}$ for each group was calculated as the fluorescence ratio of red to green and expressed as a multiple of the fluorescence ratio in the control groups. All experiments were repeated six times.

ATP content determination. ATP was measured with an ATP Determination Kit (Invitrogen Corp., Carlsbad, CA, USA). Briefly, either liver tissue $(1: 10 \mathrm{wt} / \mathrm{vol})$ or cells $\left(10^{6} \mathrm{cell} / \mathrm{ml}\right)$ were resuspended in a reaction buffer containing $1 \mathrm{mM}$ dithiothreitol, $0.5 \mathrm{mM}$ luciferin and $12.5 \mu \mathrm{g} / \mathrm{ml}$ luciferase. After the solutions were gently mixed, intensity readings for the above mixtures were measured with an Infinite M200 Microplate Reader. The ATP content in the samples was calculated using an ATP standard curve. The ATP contents were expressed as the percentage of the level observed in the control groups.

Cell viability assay. Cell viability was analyzed using a Cell Counting Kit-8 (CCK-8) (Dojindo Laboratories, Kumamoto, Japan). Briefly, $1 \times 10^{4}$ cells were seeded into 96-well plates. After being treated with $\mathrm{Cd}, 10 \mu \mathrm{l}$ of CCK-8 solution was added to each well. The cells were then incubated at $37^{\circ} \mathrm{C}$ for $2 \mathrm{~h}$. After incubation, the $\mathrm{OD}$ value at $450 \mathrm{~nm}$ was determined with an Infinite M200 Microplate Reader. The results were expressed as a percentage of the values of the control set at $100 \%$. 
a
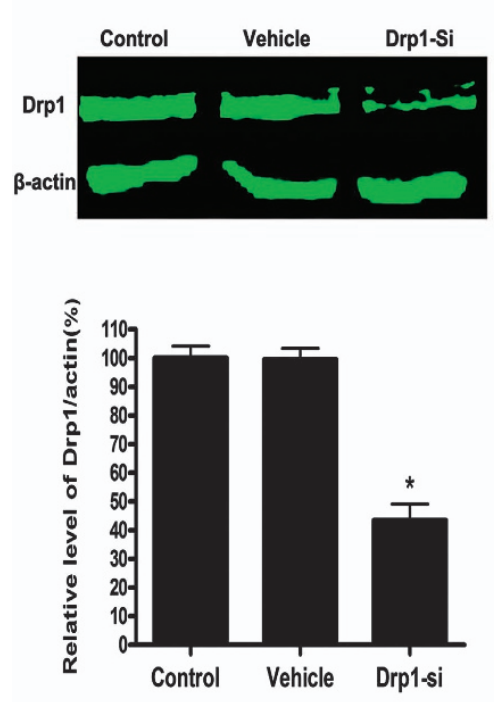

\section{b}
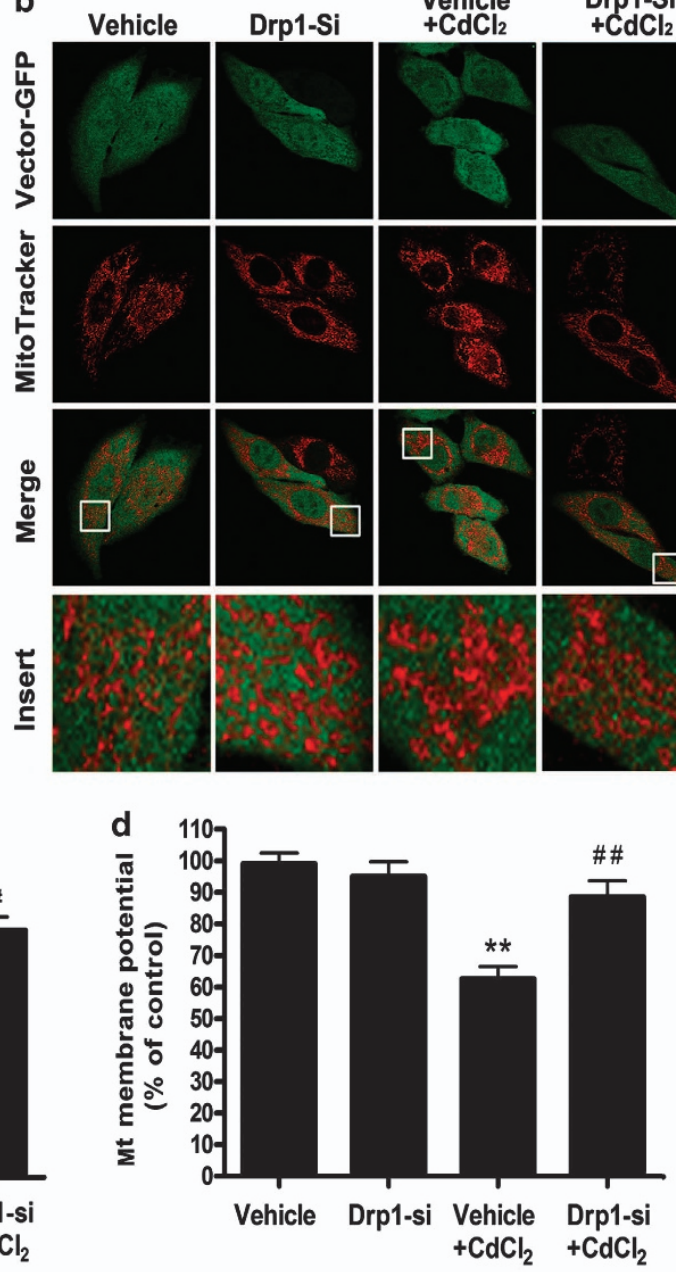

e
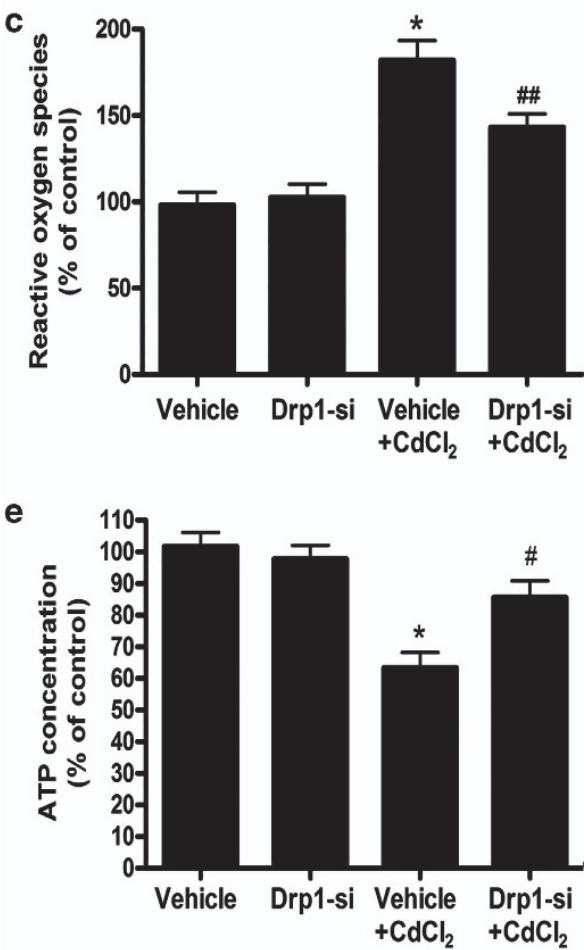

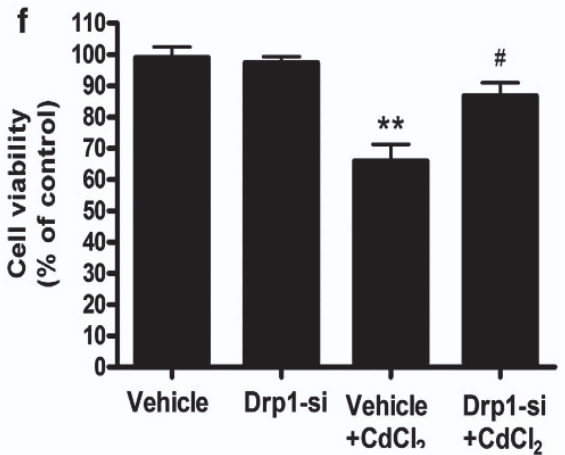

Figure 6 Drp1 silencing attenuated $\mathrm{CdCl}_{2}$-induced mitochondrial fragmentation and mitochondrial dysfunction in L02 cells. (a) Representative immunoblot of Drp1 (84 kDa) in L02 cells silenced by a commercial siRNA vector. (b) After L02 cells were treated with $12 \mu \mathrm{M} \mathrm{CdCl}$ for $12 \mathrm{~h}$, the effects of the Drp1 silencing vector (green) on mitochondrial fragmentation were detected. Drp1 silencing reversed ROS overproduction (c), $\Delta \Psi \mathrm{m}$ loss (d), ATP decline (e) and the reduction of cell viability (f) in $\mathrm{CdCl}_{2}$ treated L02 cells. The values are presented as the mean \pm S.E.M, all experiments were repeated six times, ${ }^{*} P<0.05,{ }^{* \star} P<0.01$ versus the control group and ${ }^{\#} P<0.05$ and $\# P<0.01$ versus the $\mathrm{CdCl}_{2}(12 \mu \mathrm{M})$ group

Transmission electron microscopy and light microscopy. Frozen liver tissues were rinsed in PBS and fixed in $10 \%$ buffered formaldehyde for $72 \mathrm{~h}$ before being embedded in paraffin. The sections were deparaffinized, rehydrated with graded ethanol and quenched with PBS three times. Then, liver sections (5-mm thick) were stained with hematoxylin and eosin for observation under a light microscope. For the transmission electron microscopy studies, the liver sections were washed with PBS and cut into small pieces $\left(1 \mathrm{~mm}^{3}\right)$. After fixation with $2.5 \%$ glutaraldehyde, which was pre-cooled to $4{ }^{\circ} \mathrm{C}$, the livers were post-fixed with $2 \%$ osmium tetroxide in $0.1 \mathrm{M}$ PBS, rinsed, dehydrated and embedded. Random thin sections $(0.05 \mu \mathrm{m})$ were cut using glass knives, collected on naked coppermeshed grids and stained with uranyl acetate and lead citrate. The sections were examined and viewed using a Hitachi-7500 electron microscope (Hitachi-7500, Hitachi Co., Tokyo, Japan).

Western blot analysis. Protein samples that were isolated from rat liver tissues and L02 cells were separated by SDS-PAGE. After protein transfer 


$$
\text { a }
$$
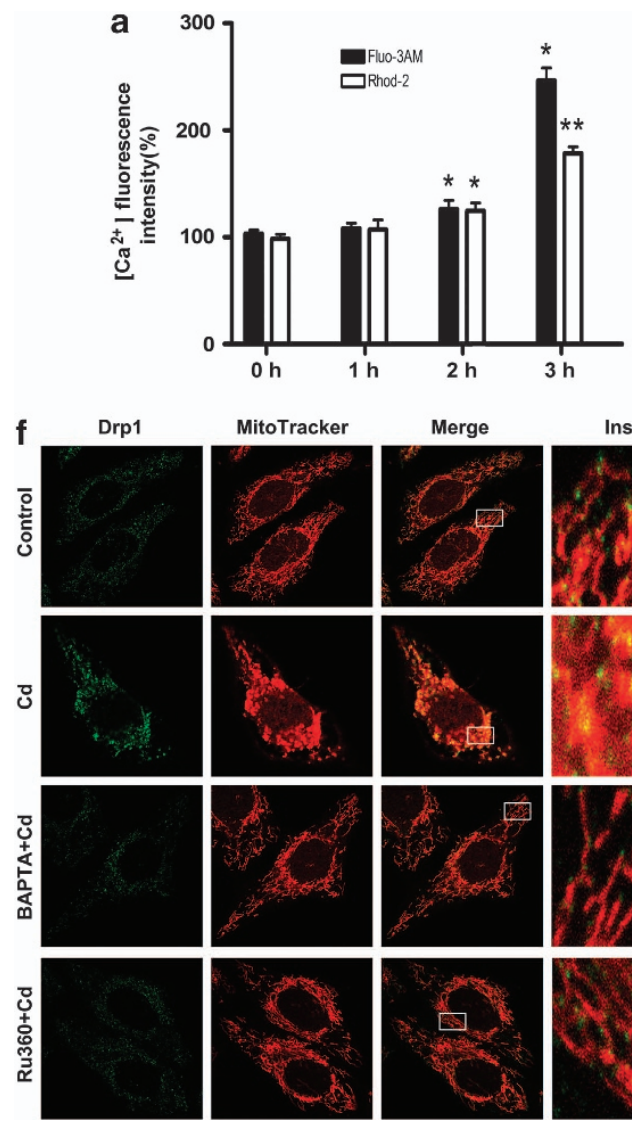

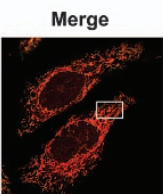

Insert
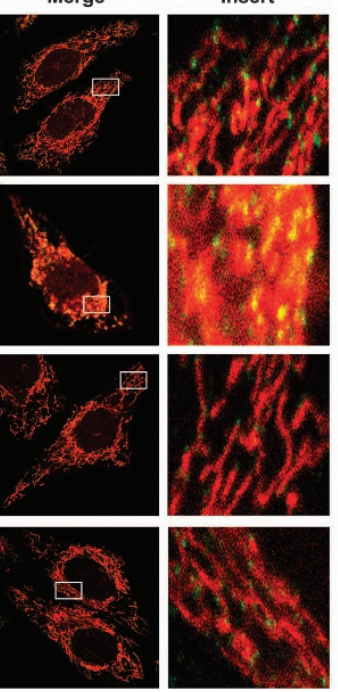

b

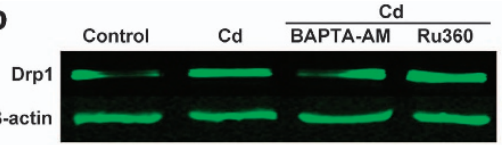

c

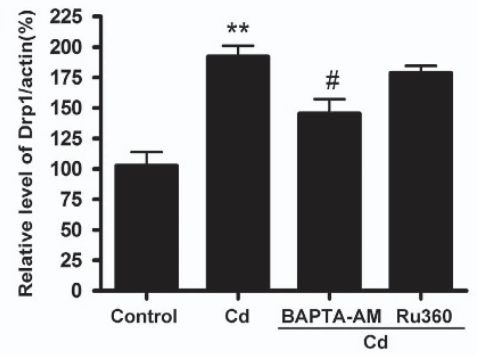

d

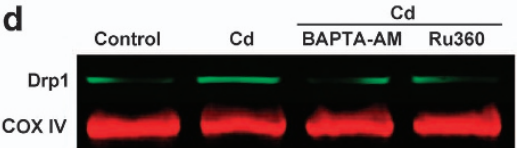

Figure 7 The effects of $\mathrm{CdCl}_{2}$ on Drp1 are related to $\left[\mathrm{Ca}^{2+}\right]_{i}$ elevation and $\left[\mathrm{Ca}^{2+}\right]_{m}$ uptake. (a) Fluo 3-AM and Rhod-2 were used to monitor the effects of $\mathrm{Cd}$ on $\left[\mathrm{Ca}^{2+}\right]_{i}$ and $\left[\mathrm{Ca}^{2+}\right]_{\mathrm{m}}$ in L02 cells, respectively. Representative immunoblot of the protein levels of Drp1 in L02 cells (b) and in isolated mitochondria (d). The quantification analysis in figures $(\mathbf{c})$ and $(\mathbf{e})$ are for figures $(\mathbf{b})$ and $(\mathbf{d})$, respectively. The values are presented as the mean \pm S.E.M, all experiments were repeated six times. ${ }^{*} P<0.05,{ }^{* *} P<0.01$ versus the control group and ${ }^{\#} P<0.05$ versus the $\mathrm{CdCl}_{2}(12 \mu \mathrm{M})$ group. (f) Confocal microscope scanning photographs indicated the changes of mitochondrial morphology and mitochondrial localization of Drp1 in treated L02 cells. Red: Mito-Tracker Red CMXRos, Green: Drp1. BAPTA-AM, a specific [Ca $\left.{ }^{2+}\right]_{i}$ chelator. Ru360, an inhibitor of $\left[\mathrm{Ca}^{2+}\right]_{\mathrm{m}}$ uptake

to nitrocellulose membranes, the membranes were blocked and incubated with various primary antibodies at $4{ }^{\circ} \mathrm{C}$ overnight. We used the following primary antibodies for the western blots: rabbit anti-mitofusin 1 (Mfn1) (Cat. No ab104585, Abcam, Cambridge, MA, USA), rabbit anti-mitofusin 2 (Mfn2) (Cat. No ab50838, Abcam), rabbit anti-optic atrophy 1 (OPA1) (Cat. No ab90857, Abcam), mouse anti-Drp1 (Cat. No ab611113, BD Biosciences, MA, USA) for rats or mouse anti-Drp1 for human (Cat. No sc-271583, Santa Cruz Biotechnology), rabbit anti-fission 1 (Fis1) (Cat. No ab71498, Abcam) and mouse anti-actin (Cat. No sc-81178, Santa Cruz Biotechnology). The special Odyssey secondary antibodies were IRDye680 or IRDye800 donkey anti-rabbit antibody, IRDye680 donkey anti-goat antibody and IRDye800 donkey anti-mouse IgG antibody. The fluorescent signals were detected and quantified using an Odyssey Infrared Imaging System (LI-COR, Lincoln, NE, USA). For the mitochondrial Drp1 protein level analysis, mitochondrial extracts were isolated from rat liver tissue and L02 cells with the Tissue and Cell Mitochondria Isolation Kit (Beyotime Company). Then, the mitochondrial Drp1 protein levels were determined as described above.

Drp1 siRNA vector construction and transfection. An siRNA targeting human Drp1 was designed by Invitrogen Corporation (Shanghai, China) and cloned into the pcDNA 6.2-GW/EmGFPmiR vector. Negative controls siRNA was also provided by Invitrogen Corporation. The constructed vectors were transfected into L02 cells using optimum-minimum essential medium with Lipofectamine 2000 (Invitrogen, Rockville, MD, USA). At $48 \mathrm{~h}$ post-transfection, the L02 cells were treated with $12 \mu \mathrm{M} \mathrm{CdCl}_{2}$ for $12 \mathrm{~h}$. The knockdown efficiency of the Drp1 siRNA was determined by western blot.
Measurement of intracellular calcium $\left(\left[\mathrm{Ca}^{2+}\right]_{\mathrm{i}}\right)$ and mitochondrial calcium $\left(\left[\mathrm{Ca}^{2+}\right]_{\mathrm{m}}\right)$. The concentrations of $\left[\mathrm{Ca}^{2+}\right]_{i}$ and $\left[\mathrm{Ca}^{2+}\right]_{\mathrm{m}}$ were monitored using Fluo 3-AM and Rhod-2 (Dojindo Laboratories), respectively. Briefly, $1 \times 10^{4}$ cells were seeded into 96 -well plates. L02 cells were pretreated with $10 \mu \mathrm{M}$ BAPTA-AM or $20 \mu \mathrm{M}$ Ru360 for $30 \mathrm{~min}$ and then exposed to Cd. After being washed with HBSS solution without $\mathrm{Ca}^{2+}$ and $\mathrm{Mg}^{2+}$, $\mathrm{L} 02$ cells were then loaded with HBSS solution containing $1 \mu \mathrm{M}$ Fluo 3 -AM or $2 \mu \mathrm{M}$ Rhod-2 at $37^{\circ} \mathrm{C}$ for $30 \mathrm{~min}$ in the dark. The stained cells were washed and incubated with HBSS solution for another $30 \mathrm{~min}$. The fluorescence of Fluo 3-AM and Rhod2 were measured at 480/525 and 540/605 excitation/emission wavelengths with an Infinite M200 Microplate Reader, respectively. The experiment was repeated six times and fluorescence intensity was expressed as the fold increase compared with the controls.

Statistical analysis. All of the experimental data are expressed as the mean \pm S.E.M., and each experiment was performed at least three times. The data comparisons among the groups were performed using a non-parametric, oneway ANOVA, and $P<0.05$ was considered statistically significant.

\section{Conflict of Interest}

The authors declare no conflict of interest.

Acknowledgements. This work was supported by a grant from the National Natural Science Foundation of China (No. 31170800). We appreciate Dr Qi Zhao, Dr Weixia Duan, Dr Yan Wang and Dr Hongjuan Wu from our department for their 
generous technical assistance in the animal sample collection. We thank Professor Linhong Deng, Dr Rong Xu and Dr Feng Lin from Chongqing University for their professional assistance in the time-lapse microscopy analysis.

1. Waisberg M, Joseph P, Hale B, Beyersmann D. Molecular and cellular mechanisms of cadmium carcinogenesis. Toxicology 2003; 192: 95-117.

2. Klaassen $\mathrm{CD}$, Liu J, Choudhuri S. Metallothionein: an intracellular protein to protect against cadmium toxicity. Annu Rev Pharmacol Toxicol 1999; 39: 267-294.

3. Satarug S, Baker JR, Urbenjapol S, Haswell-Elkins M, Reilly PE, Williams DJ et al. A global perspective on cadmium pollution and toxicity in non-occupationally exposed population. Toxicol Lett 2003; 137: 65-83.

4. Akesson A, Lundh T, Vahter M, Bjellerup P, Lidfeldt J, Nerbrand $C$ et al. Tubular and glomerular kidney effects in Swedish women with low environmental cadmium exposure. Environ Health Perspect 2005; 113: 1627-1631.

5. Schutte R, Nawrot TS, Richart T, Thijs L, Vanderschueren D, Kuznetsova T et al. Bone resorption and environmental exposure to cadmium in women: a population study. Environ Health Perspect 2008; 116: 777-783.

6. Menke A, Muntner P, Silbergeld EK, Platz EA, Guallar E. Cadmium levels in urine and mortality among U.S. adults. Environ Health Perspect 2009; 117: 190-196.

7. Shaikh ZA, Vu TT, Zaman K. Oxidative stress as a mechanism of chronic cadmiuminduced hepatotoxicity and renal toxicity and protection by antioxidants. Toxicol Appl Pharmacol 1999; 154: 256-263.

8. Rikans LE, Yamano T. Mechanisms of cadmium-mediated acute hepatotoxicity. J Biochem Mol Toxicol 2000; 14: 110-117.

9. Satarug S, Moore MR. Adverse health effects of chronic exposure to low-level cadmium in foodstuffs and cigarette smoke. Environ Health Perspect 2004; 112: 1099-1103.

10. Kuester RK, Waalkes MP, Goering PL, Fisher BL, McCuskey RS, Sipes IG. Differential hepatotoxicity induced by cadmium in Fischer 344 and Sprague-Dawley rats. Toxicol Sci 2002; 65: 151-159

11. Cannino G, Ferruggia E, Luparello C, Rinaldi AM. Cadmium and mitochondria. Mitochondrion 2009; 9: 377-384.

12. Belyaeva EA, Dymkowska D, Wieckowski MR, Wojtczak L. Mitochondria as an important target in heavy metal toxicity in rat hepatoma AS-30D cells. Toxicol Appl Pharmacol 2008; 231: 34-42.

13. Al-Nasser IA. Cadmium hepatotoxicity and alterations of the mitochondrial function. J Toxicol Clin Toxicol 2000; 38: 407-413.

14. Chen $\mathrm{H}$, Chan DC. Emerging functions of mammalian mitochondrial fusion and fission. Hum Mol Genet 2005; 14 (Spec No. 2): R283-R289.

15. Detmer SA, Chan DC. Functions and dysfunctions of mitochondrial dynamics. Nat Rev Mol Cell Biol 2007; 8: 870-879.

16. Su B, Wang X, Zheng L, Perry G, Smith MA, Zhu X. Abnormal mitochondrial dynamics and neurodegenerative diseases. Biochim Biophys Acta 1802; 1: 135-142.

17. Gomez-Lazaro M, Bonekamp NA, Galindo MF, Jordan J, Schrader M. 6-Hydroxydopamine (6-OHDA) induces Drp1-dependent mitochondrial fragmentation in SH-SY5Y cells. Free Radic Biol Med 2008; 44: 1960-1969.

18. Wang X, Su B, Liu W, He X, Gao Y, Castellani RJ et al. DLP1-dependent mitochondrial fragmentation mediates 1-methyl-4-phenylpyridinium toxicity in neurons: implications for Parkinson's disease. Aging Cell 10: 807-823.

19. Barsoum MJ, Yuan H, Gerencser AA, Liot G, Kushnareva Y, Graber S et al. Nitric oxideinduced mitochondrial fission is regulated by dynamin-related GTPases in neurons. EMBO J 2006; 25: 3900-3911.
20. Dorta DJ, Leite S, DeMarco KC, Prado IM, Rodrigues T, Mingatto FE et al. A proposed sequence of events for cadmium-induced mitochondrial impairment. J Inorg Biochem 2003; 97: 251-257.

21. Wang Y, Fang J, Leonard SS, Rao KM. Cadmium inhibits the electron transfer chain and induces reactive oxygen species. Free Radic Biol Med 2004; 36: 1434-1443.

22. Wang $X$, Su B, Siedlak SL, Moreira PI, Fujioka H, Wang $Y$ et al. Amyloid-beta overproduction causes abnormal mitochondrial dynamics via differential modulation of mitochondrial fission/fusion proteins. Proc Natl Acad Sci USA 2008; 105: 19318-19323.

23. Shenouda SM, Widlansky ME, Chen K, Xu G, Holbrook M, Tabit CE et al. Altered mitochondrial dynamics contributes to endothelial dysfunction in diabetes mellitus. Circulation 124: 444-453.

24. Yung LY, Lam WS, Ho MK, Hu Y, Ip FC, Pang $\mathrm{H}$ et al. Astragaloside IV and cycloastragenol stimulate the phosphorylation of extracellular signal-regulated protein kinase in multiple cell types. Planta Med 2012; 78: 115-121.

25. Belyaeva EA, Glazunov VV, Korotkov SM. Cyclosporin A-sensitive permeability transition pore is involved in $\mathrm{Cd}(2+)$-induced dysfunction of isolated rat liver mitochondria: doubts no more. Arch Biochem Biophys 2002; 405: 252-264.

26. Lemarie A, Lagadic-Gossmann D, Morzadec C, Allain N, Fardel O, Vernhet L. Cadmium induces caspase-independent apoptosis in liver Hep3B cells: role for calcium in signaling oxidative stress-related impairment of mitochondria and relocation of endonuclease $G$ and apoptosis-inducing factor. Free Radic Biol Med 2004; 36: 1517-1531.

27. Wang X, Su B, Lee HG, Li X, Perry G, Smith MA et al. Impaired balance of mitochondrial fission and fusion in Alzheimer's disease. J Neurosci 2009; 29: 9090-9103.

28. Smirnova E, Shurland DL, Ryazantsev SN, van der Bliek AM. A human dynamin-related protein controls the distribution of mitochondria. J Cell Biol 1998; 143: 351-358.

29. Lutz AK, Exner N, Fett ME, Schlehe JS, Kloos K, Lammermann K et al. Loss of parkin or PINK1 function increases Drp1-dependent mitochondrial fragmentation. J Biol Chem 2009; 284: 22938-22951.

30. Cereghetti GM, Stangherlin A. Martins de Brito O, Chang CR, Blackstone C, Bernardi P, et al. Dephosphorylation by calcineurin regulates translocation of Drp1 to mitochondria. Proc Natl Acad Sci USA 2008; 105: 15803-15808.

31. Breckenridge DG, Stojanovic M, Marcellus RC, Shore GC. Caspase cleavage product of BAP31 induces mitochondrial fission through endoplasmic reticulum calcium signals, enhancing cytochrome c release to the cytosol. J Cell Biol 2003; 160 1115-1127.

32. Hom JR, Gewandter JS, Michael L, Sheu SS, Yoon Y. Thapsigargin induces biphasic fragmentation of mitochondria through calcium-mediated mitochondrial fission and apoptosis. J Cell Physiol 2007; 212: 498-508.

33. Yoon Y. Regulation of mitochondrial dynamics: another process modulated by $\mathrm{Ca} 2+$ signals? Sci STKE 2005; 2005: pe18.

34. Brooks $C$, Wei $Q$, Feng $L$, Dong G, Tao $Y$, Mei $L$ et al. Bak regulates mitochondrial morphology and pathology during apoptosis by interacting with mitofusins. Proc Natl Acad Sci USA 2007; 104: 11649-11654.

35. Xu SC, He MD, Zhong M, Zhang YW, Wang Y, Yang $L$ et al. Melatonin protects against Nickel-induced neurotoxicity in vitro by reducing oxidative stress and maintaining mitochondrial function. J Pineal Res 2010; 49: 86-94.
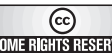

Cell Death and Disease is an open-access journal published by Nature Publishing Group. This work is licensed under the Creative Commons Attribution-NonCommercial-No Derivative Works 3.0 Unported License. To view a copy of this license, visit http://creativecommons.org/licenses/by-nc-nd/3.0/ 